\title{
An IoT and Wearable Technology Hackathon for Promoting Careers in Computer Science
}

\author{
Jake Rowan Byrne, Katriona O'Sullivan, and Kevin Sullivan
}

\begin{abstract}
This paper explores the use of a constructivist 21st-century learning model to implement a week-long workshop, delivered as a "hackathon," to encourage preuniversity teenagers to pursue careers in STEM, with a particular emphasis on computer science. For Irish preuniversity students, their experience of computing can vary from word processing to foundational programming, and while many schools are looking to introduce more ICT into the classroom, many students are left with a narrow view of what computer science is all about. Twenty-one students participated in the workshop and completed pre- and post-surveys, and a free word association exercise in the areas of computing and careers in computing. Analysis revealed that students' motivation to learn about the design process, programming, inputs and outputs, and wearable technology (wearables)/Internet of Things (IoT) increased following participation. There were also increases in confidence in inputs and outputs and wearables/IoT following participation, as well as changes in the computing word associations, with students associating computing more with computer programming terms rather than general terms such as the Internet. The findings suggest that the combination of a hackathon event and a model for 21 st century learning can be effective in motivating and increasing the self-efficacy of preuniversity teenagers in a number of emerging technological contexts such as IoT and wearables.
\end{abstract}

Index Terms-Computer science education, creativity, design thinking, Internet of Things (IoT), problem solving, prototypes, teamwork, wearable technologies.

\section{INTRODUCTION}

$\mathbf{T}$ HE USE of "hackathons" [1]-[3] and hackathon-like activities are a growing trend to promote engagement in STEM activities, but limited work to date has explored how they can be harnessed for pedagogical outcomes [2]. Furthermore, some research has explored changes in students perceptions of computer science after engaging in a hackathon activity [3], but the details are limited and suggest further research is required.

This paper will examine students' perceptions of, and attitudes toward, computer science, before and after engaging in a collaborative computing workshop involving both software and hardware, structured as a wearables [4]-[6] and Internet

Manuscript received October 5, 2015; revised March 19, 2016, August 18, 2016, and October 18, 2016; accepted October 19, 2016. Date of publication November 23, 2016; date of current version February 1, 2017.

The authors are with the Centre for Research in IT in Education, School of Education and School Computer Science and Statistics, Trinity College Dublin, University of Dublin, Dublin D2, Ireland (e-mail: jake@bridge21.ie; kevin@bridge21.ie; osullk14@tcd.ie).

Color versions of one or more of the figures in this paper are available online at http://ieeexplore.ieee.org.

Digital Object Identifier 10.1109/TE.2016.2626252 of Things (IoT) [7], [8] hackathon. The aim of the workshop is to give students a greater appreciation of what computing can involve in practice, and to introduce them to programming hardware interfaces for real world problems.

Bridge21 is an education project that aims to develop and promote an innovative, 21st-century learning methodology in schools, through a social constructivist pedagogy. This workshop was delivered using the Bridge21 pedagogical model for collaborative, technology-mediated, and projectbased learning [9], [10].

The participating students all had previous Bridge 21 workshop experience in which they became familiar with the model and had learned some programming skills using tools such as Blockly and Scratch [10]. These technologies are designed to introduce programming concepts and functionality to novice programmers. The students also experimented with alternative human/computer interfaces using Windows Kinect, Makey Makey, and other devices.

This paper focuses on a workshop that builds on these experiences by focusing on wearables, IoT, robotics, and home automation. The format was a four-day hackathon where each team had to prototype and develop a marketing strategy for a "product" by lunchtime on day four.

In the course of the workshop, students worked in teams and took on various roles covering the technical, creative director, marketing, and project management aspects of the work. Using a range of technologies, each team built full or partial models for their ideas, including software and the creation of a marketing campaign. The workshop culminated with each team making a Dragon's Den/Shark Tank-style pitch to "sell" their idea.

\section{BACKGROUND}

\section{A. Projects for Promoting Careers in STEM}

STEM education is a much-discussed topic as countries move toward an information society [4], [8], [11]-[14]. The literature in this area varies, from practical projects that outline learning experiences and approaches [4], [10], [12], [15]-[17], to those that talk about STEM education as a phenomenon in general [8], [13], [14]. Although there are differing views as to the best approach to take-integrative, problem/solution, or enquiry-based learning - there is consensus that there is a need for more STEM graduates.

Roberts [18] argued that STEM education is more than teaching STEM domain knowledge, but also requires the 
inclusion of 21st-century "soft" skills such as teamwork, creativity, problem solving, and inquisitive thinking. Roberts [18] also emphasized the need for learning domain knowledge through "authentic problem solving in rich social, cultural and functional contexts." These are all necessary to prepare learners for the ever-shifting landscapes that are found in STEM disciplines.

\section{B. Hackathons}

A hackathon can be described as an event, usually $24-48 \mathrm{~h}$ in duration, that involves a team-based "problem-focused computer programming" activity [1]. It usually involves prototyping some digital artifact and pitching or presenting that prototype. One of the motivating factors in a hackathon is the focus on a social or cultural issue that has some significance to the participants. The hackathon phenomenon seeks to combine both the "authentic problem solving in rich social, cultural, and functional contexts" and the rich team dynamics that Roberts argued for.

A number of works have made some attempt to explore pedagogical approach in hackathon-like activities [2], [19], [20]. These fall short on the pedagogical underpinning as they are largely exploratory in nature and have a limited theoretical and practical basis. They do, however, suggest that hackathon-like activities can offer a novel approach to designing practical and contextualized learning experiences.

It has been suggested that activities that emphasize creativity, design, and problem solving are well suited to contextualize STEM subjects for diverse groups of students [21]. A focus on real-world problems is central to this approach. The desire for diversity and reach has led to a number of different hackathon-like approaches being used to try and engage preuniversity students in STEM subjects [22]. Hackathons, and other "maker" events that focus on real-world problems, have been used to promote diversity in computer science by promoting female engagement [23]; one such approach would be the inclusion of wearables as a problem area [6], [24].

Hackathons therefore provide an excellent framework within which to develop effective and inclusive STEM activities, but this approach does not explicitly deal with how to support 21 st-century skills.

\section{21st-Century Learning}

There is a wider push for reforms in education toward 21 st-century skills [25], [26]. These reforms are generally aimed at making education provide more opportunities for developing key skills such as teamwork, effective communication, and critical thinking [27]. To facilitate the 21st-century learner, there is a need for educational practices to move to a more student-centered approach. One such approach used successfully in providing 21 st-century learning experiences in a computer science context is the social constructivist Bridge21 model [10].

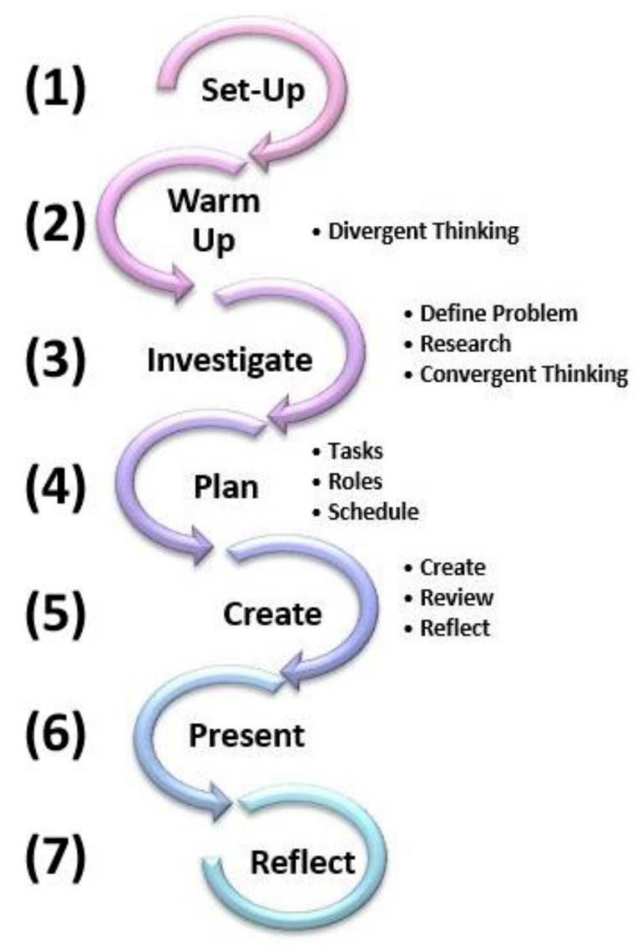

Fig. 1. Bridge21 activity model. Describes the generalized form a Bridge 21 activity follows, which can be compressed or expanded depending on content to be covered.

\section{DESIGN}

\section{A. Bridge21 Pedagogy and Model}

The workshop was based on the Bridge21 model for 21st-century learning, which emphasizes teamwork, learning by doing and technology-mediated project work [9]. The Bridge21 pedagogical model is a social constructivist approach that has been used in post-primary schools in the Republic of Ireland since 2007, and has been adapted for use in a wide range of subjects such as history [28] and mathematics [29]. The model was designed to foster intrinsic student motivation and learning potential through a deliberate move away from teacher-led learning [30]. Furthermore, a social constructivist approach includes discovery learning, problem solving, and collaboration. In this approach, the role of the teacher is to facilitate learning, encouraging students to problemsolve, and think for themselves. Here, Vygotsky's [31] idea of a "more able other" is leveraged through peer learning and mentorship. Similar constructivist approaches have been used to design both formal to informal learning experiences particularly when it comes to working creatively with computer programming [32].

\section{B. Bridge21 Activity Model}

The Bridge21 pedagogical model outlines the contextual elements required to deliver and facilitate an effective $21 \mathrm{C}$ learning experience; it does not, however, describe how to structure and design activities. The Bridge 21 activity model, Fig. 1, consists of seven stages to be considered when developing a 21 st-century learning experience. The activity model 
is adapted from practice and integrates elements from design thinking where teams move through stages of inspiration, ideation, and implementation [33], [34]. Although traditionally conveyed as a linear or cyclical process, the reality is that design thinking allows for a nonlinear approach where the teams can go back and revise previous stages if required [35]. The linear/cyclical layout provides a reminder that all stages are required and should be included in order to develop a comprehensive solution.

The activity model was used in the development of the hackathon activities discussed in this paper.

\section{Before the Hackathon}

All of the students had previously attended Bridge21 workshops, so they were familiar with this approach. During their previous Bridge21 workshops [10], the students were introduced to computer programming with LEGO Mindstorms, Blockly, and Scratch. They moved from simple procedural programs, through to more complex animations, and ultimately to designing and building games. Through this process, they were introduced to computing concepts such as initialization, parallelization, looping, conditional statements, Boolean algebra, variables, and crucially testing, debugging, and refining their programs. They also had their first chance to work with inputs other than the mouse or keyboard by using Windows Kinect, Nintendo Wii, or Makey Makey. Each team finished the week creating a Scratch game that would be controlled using one of these three.

This experience allowed students to solve problems and create artifacts in a way they had not done before. They learned new technical skills, but there was also a strong emphasis on the skills mentioned by Roberts, such as teamwork and problem solving. Confidence in these areas was an important prerequisite for the workshop described here. This workshop is a next step for students who want to further develop their computing, project, and collaborative skills.

\section{Hackathon Challenge}

The design of the week was largely inspired by the hackathon movement. A traditional hackathon would normally involve teams of professionals working over an intensive 24-48 h period. Working with a younger demographic, with a more limited set of technical skills, some changes had to be made to the traditional hackathon delivery approach. The study was spread over a week since the minors could only be facilitated in their work from 9:30 A.M. to 3:30 P.M. each day. The first day, which could be seen as separate to the main hackathon activity, also provided a more traditional educational workshop that introduced the basics of inputs and output using Python and Raspberry Pi computers. During the following three days, the teams worked more independently, using design thinking to come up with their own idea, prototype it, and finally present their concept on day four. The last three days are more in line with a hackathon approach, where real-world problems are tackled, leading to a prototype idea using the available resources. In line with the social constructivist approach, there is a greater emphasis

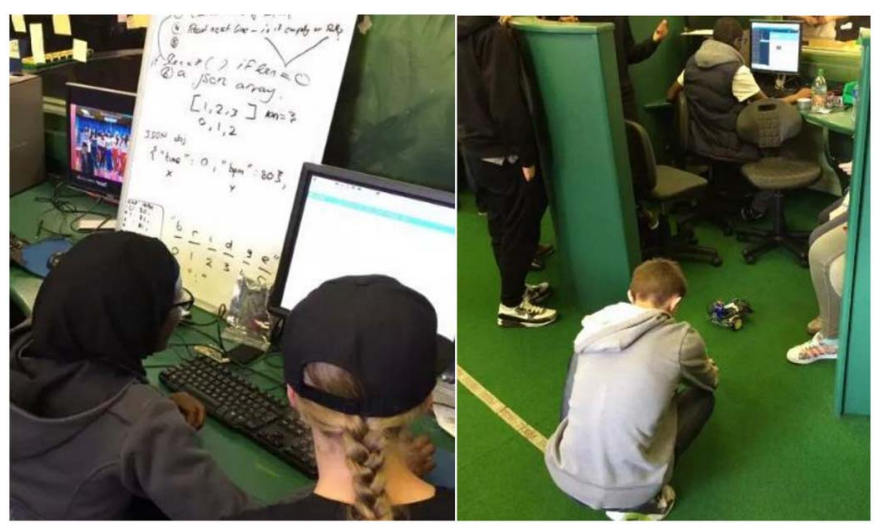

Fig. 2. Teams working on their prototypes in the Bridge 21 learning space. Left: Team sketches out pseudo code for their heartrate monitor. Right: A team tests their robot on the floor, and a team pod can be seen in the background.

on the processes the students work through, rather than just a complete or finished product.

\section{E. Technical Infrastructure}

Each team had access to the following technologies: a Raspberry Pi [36] running Raspbian OS with an Apache webserver, PHP and Python; Arduino Uno [37] boards; a robotic vehicle chassis with onboard motor controller and Grove [38] add-ons for both Arduino and Raspberry Pi; and a wide range of inputs (heart-rate sensor, light detector, switch, etc.) and outputs (LEDs, servos, sound etc.).

Each team also had a camera, microphone, and twonetworked Microsoft Windows PCs available to them throughout the week in a dedicated team "pod"; see Fig. 2. Having only two computers per team is intentional [39] to promote communication and collaboration to complete tasks. This approach also promotes paired programming, which has been shown to improve students' confidence in programming and may also help promote diversity [40].

\section{F. Mentoring and Facilitation}

One lead facilitator and three mentors were present throughout the hackathon, giving a 5:1 student/facilitator ratio. The lead facilitator had a background in mechatronic engineering, while the other three mentors had a computer science background. The mentors were not assigned to any particular group and were advised to only intervene if help was requested. This was to promote student ownership of the problems, and to simulate having to request expert advice, as one might in industry. This approach complements Vygotsky's [31] idea of providing a more able other, to help where needed but to also step back when not required. Technical knowledge and solutions were provided by the mentors, but care was taken to guide the participants toward the solutions and to model the process, rather than simply providing solutions.

\section{G. Hackathon Structure}

As the hackathon took place over a four-day period, each day was designed to move the students toward completion. 
Day one was used to deliver the technical knowledge required to engage meaningfully with the task of developing a wearable, IoT, home automation, or robotic solution by the week's end. Therefore, the first day focused on stages 1-3 in the activity model, largely exploring domain knowledge as part of the investigate stage.

Day two focused on developing and planning what they were going to design and prototype, based around a future technology workshop [41], and they also started making stages $3-5$ in the activity model.

Day three was largely dedicated to stage 5 , the creation stage. This stage involved the development of both a working prototype and a digital media campaign to promote their idea.

The fourth and final day focused on final modifications and the presentation of their work, followed by some reflection on what was learned during the week; stages 5-7 in the activity model.

1) Day One-Domain Knowledge: Day one started with the following.

1) "Set up stage" in which teams are formed and introductions were made. Effort was made to create gender-balanced teams. Mixed ability would normally be sought, but this group was relatively uniform as they had similar prior experience from the previous workshops.

2) "Warm up" activity designed to encourage divergent thinking. The teams were asked to brainstorm examples of computers in everyday life, with an emphasis on inputs and outputs. Examples included applications such as house alarms, ATMs, dishwashers, and smartphones. This activity got the teams working together and thinking creatively.

3) "Investigation stage" promoted convergent thinking and set the context of the activity; this took up the majority of this workshop session. Here, the teams were introduced to Python via an exercise that built on their previous knowledge of the Scratch programming environment. They were asked to find the Scratch equivalent to a list of Python commands. Once all commands had been translated, the teams were tasked with solving five progressively more complex Python problems. The commands needed to solve these tasks were present on the Python-Scratch translation sheet, enabling them to select commands from a list, in a similar fashion to the Scratch interface.

On completion of this task, the Python general-purpose input output library was introduced and students were tasked with wiring up an LED and switch, and using a Python program to activate the LED when the switch was pressed.

Finally, they were presented with code that activates the Python Scripts, using some PHP code run on an Apache Web server on the Raspberry Pi.

A final discussion was held to elicit the fact that the basic elements explored that day, namely the general use of input and output, are used in computers omnipresent in modern life. It was also emphasized that the Raspberry Pi can be easily used to model a variety of input and output actions, with the added benefit that it is easy to connect to the Internet, enabling
Web-connected objects, remote home automation and robotics, and ultimately the IoT.

This day could be seen to align most closely to traditional STEM programs where all students are expected to engage in largely the same activities and output the same results.

2) Day Two-Design Challenge: As previously stated, the four main topics for the week were wearables, IoT, robotics, and home automation. Building on these themes, the teams were asked to brainstorm under the four headings. Boards were placed around the room, and individuals could add a postit note to the board under each heading. The teams then went around and reviewed the collective ideas from the whole group. They were then asked to choose three ideas to implement, and to weigh their pros and cons. After discussing these with a facilitator, each team chose a specific design to prototype. At this stage, the facilitators acted to manage expectations and help teams decompose their problem down to an achievable prototype that would capture the essence of their overall product idea.

The teams allocated roles and started gathering the components and technologies needed to realize their ideas.

3) Day Three-Prototyping: This day was mostly dedicated to prototype development. This involved programming, making electronic circuits, building models with LEGO and other craft materials, and working with robotics kits. This learning-by-doing approach is typical of many social constructivist pedagogies. Teams were also encouraged to start thinking about and developing their pitch, which would involve the production of videos and websites needed to market their product. This day largely focused on the iterative nature of stage 5 of the activity model: create, review, and reflect.

4) Day Four-The Pitch: Throughout the week, the team members took various roles covering technical prototyping, multimedia development, marketing, and project management. The more technically inclined students gravitated toward the programming and electronics and those interested in graphic design and multimedia focused on developing video adverts and websites to promote their product for the "pitch." This differentiation was deliberate. Since the goal of the program was to expose all students to the work involved in a range of potential careers in computing, it was desirable to have a variety of applicable roles, from softer business and marketing elements to more in-depth technical fields such as programming and electronics. This approach provided all team members with the opportunity to engage in a technical project, but from different perspectives, representative of real-world projects in contrast to many other educational programs where every student would largely engage in very similar tasks.

The students then presented their prototypes and their websites with embedded video adverts to a number of academic staff selected in an ad hoc fashion from the university's Computer Science Department, who questioned the teams about the technical elements and what their market would be. No prize was awarded for the "best" product, as the aim of the week was to encourage all participants to pursue computer science; having the majority of the cohort "lose" would not be conducive to this aim. The Bridge21 approach also aims to develop intrinsic motivation and prizes, as extrinsic 
rewards tend to undermine the development of extrinsic motivation [42].

This pitch was a fundamental part of the workshop as it gave a deadline for the prototype development but also provided an opportunity for the teams to hone 21 st-century skills such as communication and presentation.

Finally, the teams were given a worksheet on which to reflect on their learning and teamwork, followed by the post-questionnaire and word association exercise.

\section{Methodology}

A total of 21 students participated in the hackathon workshop and the study, after having completed previous Bridge 21 introductory computer science activities. These participants were invited to participate in this paper due to their having expressed interest in computer science. A comparison group of 21 students was recruited from non-computer-science Bridge 21 activities to explore how the main workshop participants compared to a more general population. Ethical approval was sought and granted by the appropriate authorities and, as all participants were minors, informed consent forms were completed by the participants and their guardians.

The hackathon group and the comparison group were balanced for gender, both consisting of nine females and 12 males. The mean age of students in both cohorts was 16 . The comparison group of students were recruited opportunistically, but the experimental group was self-selecting and signed up to this workshop based on interest. Both groups had a high level of prior experience with the Bridge 21 model. The comparison group, however, had limited prior experience in terms the computer science workshop as described in Section III-C.

Pre- and post-questionnaires were adapted from existing studies [12], [16], [17] and sought to investigate students' attitudes to several aspects of the workshop content using eight subscales. The prequestionnaire was completed online at the start of day one, and the post questionnaire at the end of day four. The questionnaire used 33 statements (e.g., "I like to work with others to complete projects") and was rated on a 5-point Likert scale, with 1 as strongly disagree and 5 as strongly agree, to establish changes in students' motivation and self-efficacy in programming, design, inputs and outputs, and wearables/IoT. It also examined students' perceptions of their teamwork and problem-solving capabilities.

Centra and Gaubatz [43] suggested a strong connection between students' perceptions of a learning experience and the "actual" learning that takes place and may be subsequently tested. Although this paper did not explicitly evaluate the learning content of the hackathon, there is a potential link between students' self-efficacy and motivation and the learning of technical content during the week.

Other qualitative questions used free word association [44]-[46] as an indicator of students' attitudes toward, and perceptions of, careers in computer science and computing in general. This approach generates spontaneous responses that may not be elicited from more structured interviews or questionnaires. For the word association exercise, the participants were asked to list five words

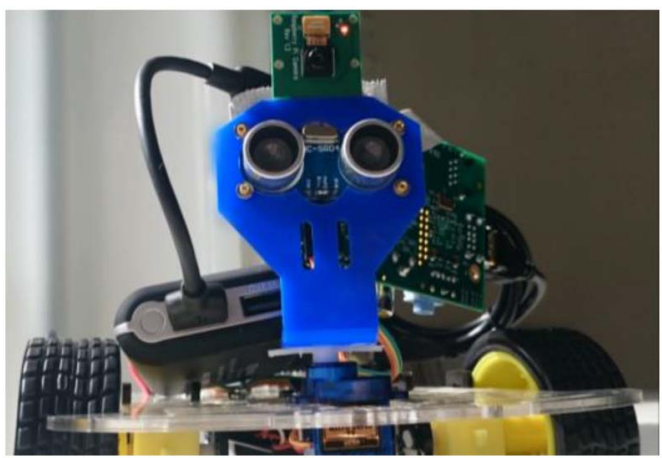

Fig. 3. "The Bridge Rover." The Raspberry Pi camera can be seen above the ultrasonic "eyes." A portable battery and Raspberry Pi computer can be seen connected in the background.

they associated with computing and five more words for careers in computing.

The students' work was also analyzed to determine which computing themes and technologies the students chose to use, and to examine the level of complexity of their technical work.

\section{DATA}

As stated, the adapted questionnaire, which sought to investigate students' attitudes to programming, design, inputs and outputs, and wearables/IoT, was administered to 42 students prior to participation in the workshop (which will be referred to as being at "time one," with testing after the workshop being at "time two").

\section{A. Prototypes}

Five prototypes were developed by the four participant teams, along with a website and video to promote each product. The products covered the full spectrum of topic areas that the workshop focused on: wearables, IoT, robotics, and home automation. Each teams' output artifacts (code, images of prototypes, and video adverts) were collected in a folder and reviewed to explore the technologies used.

"BetaFit" was a wearable personal fitness tracker and website/app. This team decided to focus on prototyping the heart monitoring functionality and relaying that information to a website. This was achieved using an Arduino and Grove heart rate sensor as the hardware, which wrote the data to a file on the Raspberry Pi that was dynamically loaded by PHP script and visualized on the website using highcharts.js JavaScript library.

"The Bridge Rover," Fig. 3, is a home security robot that can be controlled over the Internet. The prototype consisted of a Raspberry Pi, Raspberry Pi camera, and a portable USB battery mounted on an Arduino-controlled chassis. The image from the camera was relayed to a website using Mjpg-streamer open-source software. Controls were built around the image using basic HTML buttons and jQuery AJAX calls to PHP scripts that sent commands to the Arduino. The students used a mobile phone to view and control the robot remotely.

"BrijjFrijj" is a smart fridge that can detect if any of the contents have passed their "best before" date(s) or are finished and 


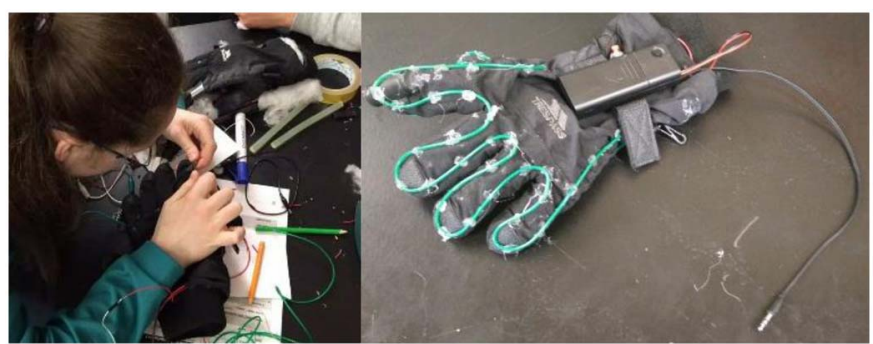

Fig. 4. Left: making the EyeGlove with glued on electroluminescent wire and audio cable to attach to phone for calls. Right: final prototype.

need to be reordered over the Internet. The prototype consisted of a Raspberry Pi with MySQL, a mobile phone, NFC tag, and a LEGO Technic and Mindstorms kit. A model fridge was constructed from LEGOs, and the phone was attached to the door of the fridge to act as an NFC tag reader. The NFC tag was attached to a milk carton so that when it was swiped across the door when putting it in the fridge, the phone launched a browser and pushed meta-data about the "best before" date and product type to the MySQL database. A webpage could then be loaded to display the status of the content, with a mock button for ordering a replacement item if the date had passed.

"EyeGlove," Fig. 4, is a wearable smart glove, with a built-in torch and heating and cooling system that connects to the user's phone to play music and make telephone calls. The students added electroluminescent wire to an old glove in order to give it a "futuristic" look and to simulate the cooling and heating elements. They also added an LED to the index finger with a switch accessible to the thumb. Finally, they added the components of an old headset so that the small finger contained the microphone and the thumb contained a speaker. They used this to make and receive calls during their demonstration.

The EyeGlove team also developed a prototype home automation system that activated one of three LEDs based on entries on a public Google Calendar. These three LEDs were to simulate three possible devices at home: a light, a cooker, and heating. The system used a PHP to parse the Google Calendar feed and execute the appropriate Python command to turn on the correct LED. As it was using a Google Calendar, it could in theory be used from anywhere.

\section{B. Comparison Versus Workshop Group}

Data collected prior to the workshop revealed that the workshop group scored significantly higher on all of the subscales of the instrument, apart from the problem-solving scale. Independent sample t-tests were undertaken on the eight pre-workshop questionnaire subscales to establish any differences that existed between the hackathon and comparison groups before participation. These results indicated that the comparison and the workshop group differed on several scales, and that the workshop group showed higher levels of motivation in design, programming, inputs and outputs, and wearables/IoT. They also had higher levels of self-efficacy with inputs and outputs and wearables/IoT. They also scored their teamwork skills higher than the comparison group; see Fig. 5.

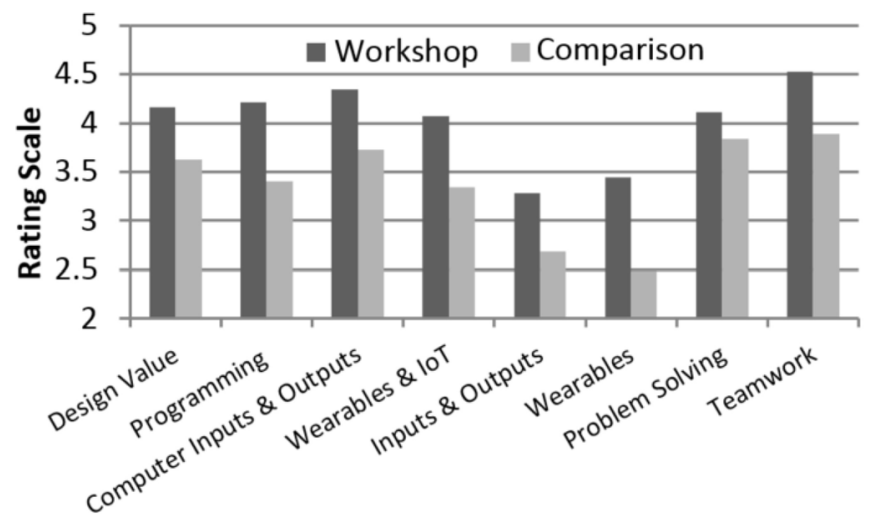

Fig. 5. Pre-workshop scores for the workshop and comparison group on the eight subscales of the questionnaire.

TABLE I

PAIRED SAMPLE T-Tests FOR THE WORKShOP GRouP

\begin{tabular}{ccccc}
\hline \hline & M_Pre & M_Post & $\mathrm{t}$ & $p$-Value \\
\hline Motivation & & & & \\
Design Value & 4.2 & 4.3 & -3.63 & .002 \\
Programming & 4.18 & 4.52 & -2.319 & .032 \\
Inputs \& Outputs & 4.38 & 4.72 & -3.327 & .004 \\
Wearables \& IoT & 4.11 & 4.47 & -2.348 & .03 \\
Self-Efficacy & & & & \\
Inputs \& Outputs & 3.35 & 4.23 & -4.574 & .001 \\
Wearables \& IoT & 3.48 & 4.48 & -5.257 & .001 \\
Problem Solving & 4.11 & 4.54 & -2.941 & .008 \\
Teamwork & 4.48 & 4.76 & -3.317 & .004 \\
\hline \hline
\end{tabular}

\section{Pre- and Post-Workshop Comparison}

The comparison group did not complete the time-two data collection and therefore are not included in the following section.

1) Pre- and Post-Questionnaire Comparison: Paired sample $t$-tests were performed for the eight subscales of the questionnaire. Significant prepost increases were observed in all eight scales; see Table I. Fig. 6 depicts increases in all four motivation subscales, following participation in the workshop, indicating that students showed significant increases in their motivation to learn about design, programming, inputs and outputs, and wearables/IoT.

The scale that measures self-efficacy showed a significant increase, see Fig. 7, indicating that students were more confident in their ability to use inputs and outputs and wearable/IoT after completing the workshop. Similarly, there was a significant increase in the problem-solving and teamwork scales following participation in the workshop, see Fig. 8, indicating that students perceived their problem-solving ability and teamwork skills had improved following participation in the workshop.

2) Word Association: Students were asked at time one (before participating in the workshop) to list the five words they associated with computers, and then were asked again at time two (after the workshop). Following participation, there was a change in these words. At time two, students listed 


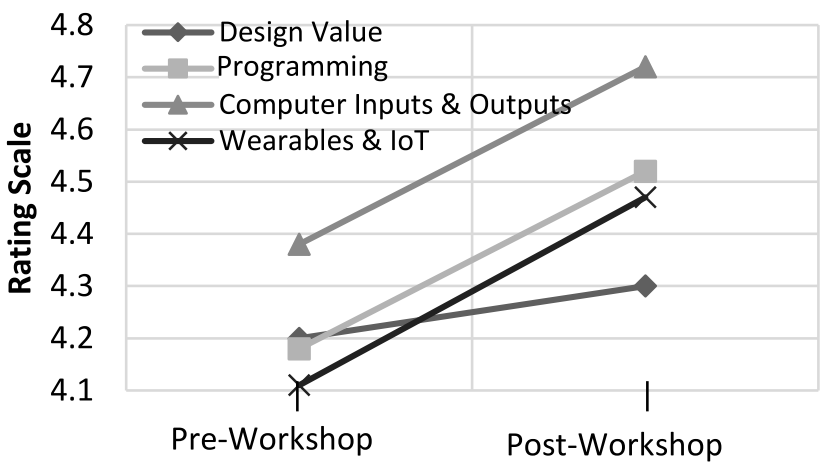

Fig. 6. Differences between the pre- and post-responses for the four motivation subscales for the workshop group.

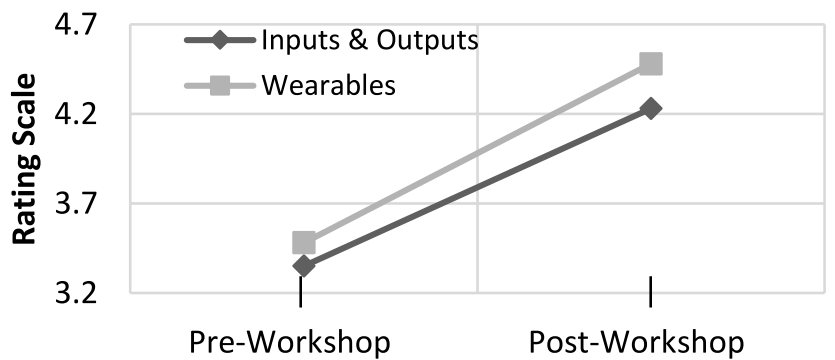

Fig. 7. Differences between the pre- and post-workshop responses for the two self-efficacy subscales for the workshop group.

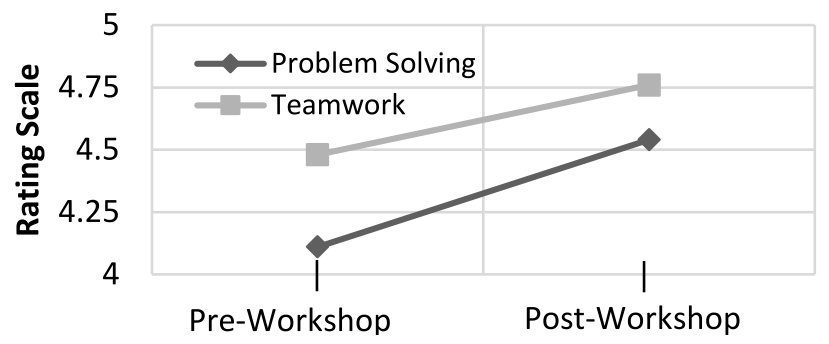

Fig. 8. Differences between the pre- and post-workshop responses for the problem-solving and teamwork scales for the workshop group.

words related to the hackathon content, a trend not observed at time one; there was a trend toward students associating computers with practical skills and technologies that they used during the week. For example, prior to the workshop, the highest percentage of students associated computers with the Internet, but following participation, terms such as programming, Python, and Raspberry Pi featured much more prominently; see Fig. 9. "Work" also appears more frequently in the post-questionnaire.

When students were asked to list five words they associated with careers in computer science at times one and two, there were changes in word content and type. Before the workshop, money had the highest percentage of associations with computer science careers. Following participation, engineering was most associated with these careers, suggesting that participation in the workshop changed students' views toward the practical content of these careers. Interestingly, challenging and teamwork appeared quite highly in the post-list, yet did not feature in the pre-list, again reflecting the development

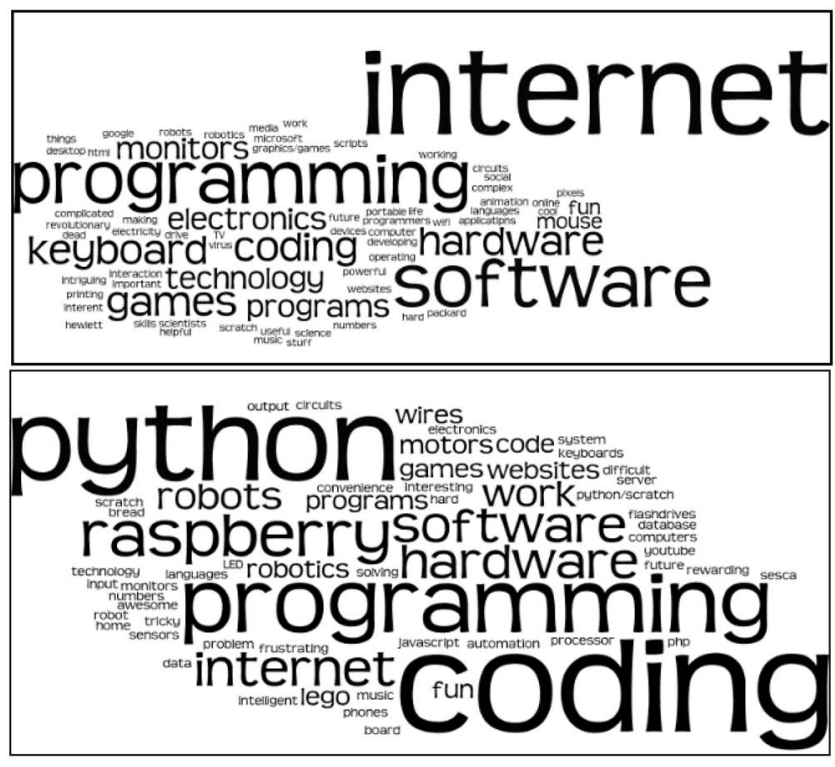

Fig. 9. Pre (top) and post (bottom) words students associated with computing.

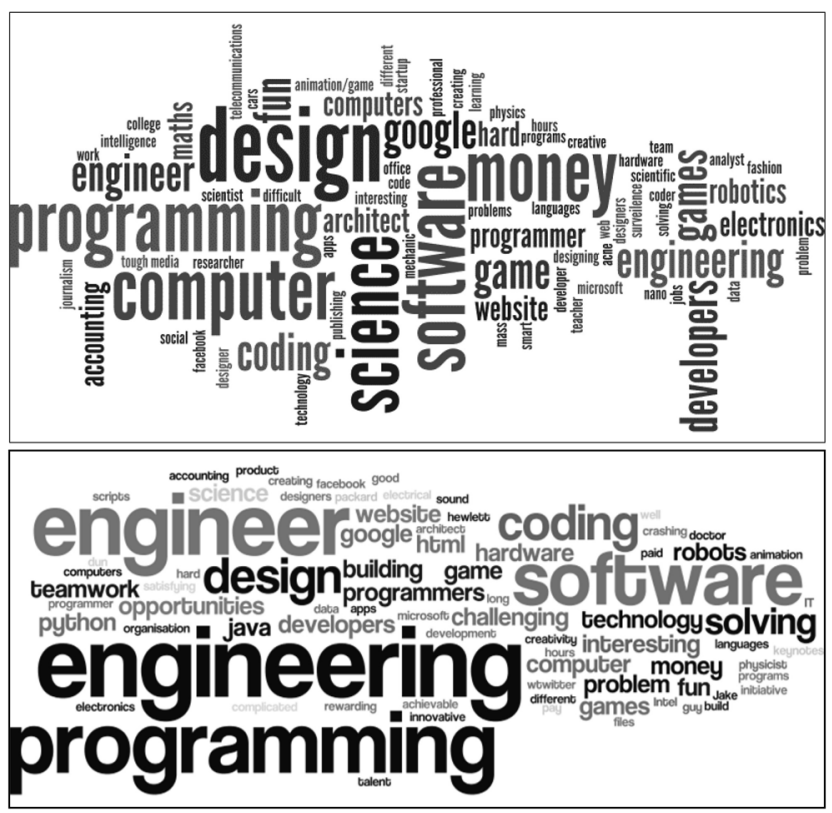

Fig. 10. Pre (top) and post (bottom) words students associated with careers in computing.

of students' knowledge toward the practicalities of the careers following exposure to the workshop content; see Fig. 10.

\section{FINDINGS}

The pre- and post-questionnaires demonstrate that the hackathon learning experience did increase the participants' self-perceived efficacy and motivation in all areas measured, despite the fact that they already self-reported high scores on the prequestionnaire when compared to the comparison group. Of particular interest is the significant increase in the selfreported self-efficacy in inputs and outputs, wearables, and IoT, as these are emerging areas of interest in the field of computer science. Combining this quantitative data with the rich prototypes developed by the teams indicates that they have 
a strong appreciation of these emerging technologies, and how they can be used in practical and meaningful contexts.

Furthermore, the word associations to computing in general seem to reflect a shift toward practical technologies that might be used in creation of computing artifacts rather than mere consumption. The word associations to careers in computing also showed a shift to more practical elements associated with the job, such as engineering, coding, and problem solving with money sliding down the scale in the post responses.

Overall the findings indicate that students received a rich learning experience that enhanced their technical confidence in developing authentic and socially orientated solutions in areas such as wearables and IoT. In addition, they reported increased confidence in 21st-century skills such as problem solving and teamwork. Furthermore, their use of language in the post-tests would suggest that they have a better idea about the approaches and technologies that may be used in careers in computing.

Further work is needed to explore the "actual" learning that occurred during the study, but the literature does suggest [43] that there is a high correlation between self-perceived learning and acquisition of traditional domain knowledge.

\section{LIMITATIONS}

The small number of participants is a major limitation of this paper. An increase in numbers should be pursued, but as the workshop is intensive, it will be difficult to scale up effectively. The participants also successfully completed an introductory computer science activity before engaging in the hackathon and were chosen based on their interest and ability to work in teams. This was evident in these students' high scores in the prequestionnaire versus those of the comparison group. Altering the selection process, or recruiting an unknown cohort lacking the same introductory training, may have a significant effect on the overall experience.

The original questionnaires [12], [16], [17] that were altered for use in this research used factor analysis for validation. This was not carried out in this research due to time restrictions; this may again limit the validity of the findings reported here. Although care was taken to substitute words such as design for science, programming for mathematics, and wearables/IoT for GPS/GIS, without formal factor analysis there is some uncertainty as to the number of factors at work in the questionnaire.

Based on facilitator feedback and observations, the workshop design might be improved by including mentors with experience in business or marketing. This could enhance the presentations and help refine the quality of the final "pitches." Further enhancements might be to include more examples of code that achieve specific goals. These code snippets may be harvested from previous instances of the workshop, so future participants can build on the work of previous groups.

Integrating this approach into the typical school/classroom would require a number of additional considerations. As this paper was focused on educational outreach for the promotion of careers in STEM, it was possible to decrease the student/mentor ratio, dedicate several days to the project, and have personnel with the experience and confidence to explore ill-defined technical problems. Using team teaching and mixing subject domain experts (e.g., business studies, graphic design/art, technology, etc.) would help reduce student/teacher ratios and provide a rich set of expertise in the class. It would also be possible to subdivide the day-long activities so that they could be spread across a number of weeks, although care would be needed in order to maintain momentum.

\section{CONCLUSION}

Work has explored pedagogical and learning outcomes in hackathon-like settings [2], [19], [20], but this has been limited. There is definite need for more work exploring how pedagogical approaches can be used to enhance hackathon learning outcomes. This paper aims to contribute to this area of study by providing a social constructivist model for hackathon design.

The findings suggest that students developed a greater appreciation of the wide range of contexts and applications involved in computer science as a career. In particular, the differentiation of roles inherent within this approach simulates the complexity of real-world projects. There are further indications that the use of wearables and IoT technologies provide students with this richer perspective of computer science applications in authentic and socially relevant contexts.

The findings indicate that the combination of a hackathon activity and a 21st-century learning model makes for an effective experience in motivating and increasing preuniversity students' self-efficacy in areas related to wearables and IoT. Furthermore, the findings suggest that this approach led to a clear shift in students' conceptions of careers in computing, which may be leveraged or replicated by CS/engineering educators.

The structured approach to constructivist learning helped participants further enhance their teamwork and problemsolving capabilities. This successful combination of technical and soft skills constitutes the ideal learning environment for 21st-century learners and promoting careers in STEM.

\section{REFERENCES}

[1] G. Briscoe and C. Mulligan, "Digital innovation: The hackathon phenomenon," Creativeworks London Working Paper, 2014

[2] J. Duhring, "PROJECT-BASED LEARNING KICKSTART TIPS: Hackathon pedagogies as educational technology," in Proc. Annu. Conf. Nat. Collegiate Inventors Innov. Alliance, 2014, p. 1.

[3] J. Mtsweni and H. Abdullah, "Stimulating and maintaining students' interest in computer science using the hackathon model," Independent J. Teach. Learn., vol. 10, pp. 85-97, 2015.

[4] B. Barker, J. Melander, N. Grandgenett, and G. Nugent, "Utilizing wearable technologies as a pathway to STEM," in Proc. Soc. Inf. Technol. Teacher Educ. Int. Conf., Chesapeake, VA, USA, 2015, pp. 1770-1776.

[5] G. T. Richard and Y. B. Kafai, "Making physical and digital games with e-textiles: A workshop for youth making responsive wearable games and controllers," in Proc. 14th Int. Conf. Interact. Design Children, Medford, MA, USA, 2015, pp. 399-402.

[6] L. Buechley, M. Eisenberg, J. Catchen, and A. Crockett, "The lilypad arduino: Using computational textiles to investigate engagement, aesthetics, and diversity in computer science education," in Proc. SIGCHI Conf. Human Factors Comput. Syst., Florence, Italy, 2008, pp. 423-432.

[7] D. Bandyopadhyay and J. Sen, "Internet of Things: Applications and challenges in technology and standardization," Wireless Pers. Commun., vol. 58, no. 1, pp. 49-69, 2011. 
[8] L. Johnson, S. Brown, M. Cummins, and V. Estrada, "The technology outlook for STEM+ education 2012-2017: An NMC horizon report sector analysis," 2012.

[9] J. Lawlor, C. Conneely, and B. Tangney, "Towards a pragmatic model for group-based, technology-mediated, project-oriented learning-An overview of the B2C model," in Technology Enhanced Learning. Quality of Teaching and Educational Reform. Heidelberg, Germany: Springer, 2010, pp. 602-609.

[10] B. Tangney, E. Oldham, C. Conneely, S. Barrett, and J. Lawlor, "Pedagogy and processes for a computer programming outreach workshop-The bridge to college model," IEEE Trans. Educ., vol. 53, no. 1, pp. 53-60, Feb. 2010.

[11] J. J. Kuenzi, Science, Technology, Engineering, and Mathematics (STEM) Education: Background, Federal Policy, and Legislative Action, Congr. Res. Service, Washington, DC, USA, 2008, pp. 1-31.

[12] G. Nugent, B. Barker, N. Grandgenett, and V. I. Adamchuk, "Impact of robotics and geospatial technology interventions on youth STEM learning and attitudes," J. Res. Technol. Educ., vol. 42, no. 4, pp. 391-408, 2010.

[13] M. Sanders, "STEM, STEM education, STEMmania," Technol. Teacher, vol. 68, no. 4, pp. 20-26, 2009.

[14] J. Williams, "STEM education: Proceed with caution," Design Technol. Educ. Int. J., vol. 16, no. 1, pp. 26-35, 2011.

[15] S. B. Fee and A. M. Holland-Minkley, "Teaching computer science through problems, not solutions," Comput. Sci. Educ., vol. 20, no. 2, pp. 129-144, 2010.

[16] G. Nugent, B. Barker, N. Grandgenett, and G. Welch, "Robotics camps, clubs, and competitions: Results from a US robotics project," in Proc. 4th Int. Workshop Teach. Robot. Teach. Robot. 5th Int. Conf. Robot. Educ. Padova (Italy), Jul. 2014, pp. 11-18.

[17] G. Nugent et al., "Measuring the impact of robotics and geospatial technologies on youth science, technology, engineering and mathematics attitudes," in Proc. World Conf. Educ. Media Technol., Honolulu, HI, USA, 2009, pp. 3331-3340.

[18] A. Roberts, "A justification for STEM education," Technol. Eng. Teacher, pp. 1-5, May/Jun. 2012.

[19] M. Skirpan and T. Yeh, "Beyond the flipped classroom: Learning by doing through challenges and hack-a-thons," in Proc. 46th ACM Tech. Symp. Comput. Sci. Educ., Kansas City, MO, USA, 2015, pp. 212-217.

[20] A. Nandi and M. Mandernach, "Hackathons as an informal learning platform," in Proc. 47th ACM Tech. Symp. Comput. Sci. Educ., Memphis, TN, USA, 2016, pp. 346-351.

[21] R. Cooper and C. Heaverlo, "Problem solving and creativity and design: What influence do they have on girls' interest in STEM subject areas?" Amer. J. Eng. Educ., vol. 4, no. 1, pp. 27-38, 2013.

[22] Y. B. Kafai et al., "Motivating and broadening participation: Competitions, contests, challenges, and circles for supporting STEM learning," in Proc. 11th Int. Conf. Learn. Sci. Learn. Becoming Pract., Boulder, CO, USA, 2014, pp. 1219-1227.

[23] G. T. Richard, Y. B. Kafai, B. Adleberg, and O. Telhan, "StitchFest: Diversifying a college hackathon to broaden participation and perceptions in computing," in Proc. 46th ACM Tech. Symp. Comput. Sci. Educ., Kansas City, MO, USA, 2015, pp. 114-119.

[24] Y. B. Kafai et al., "A crafts-oriented approach to computing in high school: Introducing computational concepts, practices, and perspectives with electronic textiles," ACM Trans. Comput. Educ., vol. 14, no. 1, p. 1, 2014.

[25] C. Dede, "Comparing frameworks for 21st century skills," in 21st Century Skills: Rethinking How Students Learn, vol. 20. Bloomington, IN, USA: Solution Tree, 2010, pp. 51-76.

[26] D. Rychen and L. Salganik, The Definition and Selection of Key Competencies: Executive Summary. Paris, France: OECD, 2005.

[27] C. Conneely, D. Murchan, B. Tangney, and K. Johnston, "21 century learning-Teachers' and students' experiences and views of the bridge21 approach within mainstream education," in Proc. Soc. Inf. Technol. Teacher Educ. Int. Conf., 2013, pp. 5125-5132.

[28] D. O’Donovan. (2015). Enquiry Based Learning at Bridge21. [Online]. Available: https://sites.google.com/site/enquirybasedlearningatbridge21/ home

[29] B. Tangney and A. Bray, "Mobile technology, maths education \& 21C learning," presented at the QScience, 2013, pp. 20-27.

[30] J. Lawlor, K. Marshall, and B. Tangney, "Bridge21-Exploring the potential to foster intrinsic student motivation through a team-based, technology-mediated learning model," Technol. Pedagogy Educ., vol. 25, no. 2, pp. $187-206,2016$.
[31] L. S. Vygotsky, Mind in Society, M. Cole, V. John-Steiner, S. Scribner, and E. Souberman, Eds. Cambridge, MA, USA: Harvard Univ. Press, 1978.

[32] Y. B. Kafai and M. Resnick, Constructionism in Practice: Designing, Thinking, and Learning in a Digital World. New York, NY, USA: Routledge, 1996.

[33] T. Brown and J. Wyatt, "Design thinking for social innovation," Develop. Outreach, vol. 12, no. 1, pp. 29-43, 2010.

[34] H. Plattner, C. Meinel, and L. Leifer, Design Thinking: UnderstandImprove-Apply. Heidelberg, Germany: Springer, 2010.

[35] C. Meinel and L. Leifer, "Design thinking research," in Design Thinking: Understand-Improve-Apply. Heidelberg, Germany: Springer, 2010.

[36] RaspberryPiFoundation. (Sep. 2015). What is a Raspberry Pi? [Online]. Available: https://www.raspberrypi.org/help/what-is-a-raspberry-pi/

[37] Arduino. (Sep. 2015). Arduino Uno. [Online]. Available: https://www.arduino.cc/en/Main/ArduinoBoardUno

[38] SeeedStudio. (Sep. 2015). Grove System. [Online]. Available: http://www.seeedstudio.com/wiki/Grove_System

[39] W. P. Dickson and M. A. Vereen, "Two students at one microcomputer," Theory Pract., vol. 22, no. 4, pp. 296-300, 1983.

[40] C. McDowell, L. Werner, H. E. Bullock, and J. Fernald, "Pair programming improves student retention, confidence, and program quality," Commun. ACM, vol. 49, no. 8, pp. 90-95, 2006.

[41] G. N. Vavoula, M. Sharples, and P. D. Rudman, "Developing the "future technology workshop' method," in Proc. Int. Workshop Interact. Design Children, Eindhoven, The Netherlands, Aug. 2002, pp. 65-72.

[42] E. L. Deci, R. Koestner, and R. M. Ryan, "Extrinsic rewards and intrinsic motivation in education: Reconsidered once again," Rev. Educ. Res., vol. 71, no. 1, pp. 1-27, 2001.

[43] J. A. Centra and N. B. Gaubatz, "Student perceptions of learning and instructional effectiveness in college courses: A validity study of SIR II," Educ. Test. Service, Princeton, NJ, USA, ETS SIR Tech. Rep. no. 9, 2005.

[44] B. Pelleg, M. Figueroa, M. VanKouwenberg, A. Fontecchio, and E. Fromm, "Implementing nanotechnology education in the high school classroom," in Proc. Frontiers Educ. Conf. (FIE), Rapid City, SD, USA, 2011, pp. F4D-1-F4D-6.

[45] K. W. Hirsh and J. J. Tree, "Word association norms for two cohorts of British adults," J. Neurolinguistics, vol. 14, no. 1, pp. 1-44, 2001.

[46] O. Ben-Zvi-Assaraf and N. Ayal, "Harnessing the environmental professional expertise of engineering students-The course: 'Environmental management systems in the industry,"' J. Sci. Educ. Technol., vol. 19, no. 6 , pp. $532-545,2010$.

Jake Rowan Byrne was born in Dublin, Ireland, in 1984. He received the B.Eng. (Hons.) degree in mechatronic engineering from Dublin City University (DCU), Dublin, in 2006, and the M.Sc. degree in technology and learning and the Ph.D. degree in computer science from the University of Dublin (Trinity College), Dublin, in 2008 and 2013.

Since 2013, he has been a Research Fellow and an STEM Programme Manager with the University of Dublin's (Trinity College) Bridge21 Educational Outreach Program. He has authored a book chapter, several articles, and is a Co-Inventor on a wearable technology patent for agriculture. His current research interests include design thinking, creativity, STEM education, higher order thinking, human-computer interaction, and active learning.

Dr. Byrne was a recipient of the John Holland Undergraduate Research Award from RINCE at DCU in 2007, and was selected for the EdTech Cultural Exchange Program by the U.S. Embassy, Dublin, in 2014.

Katriona O'Sullivan received the B.A. and Ph.D. degrees in psychology from the University of Dublin (Trinity College), Dublin, Ireland, in 2008 and 2012.

She has been a Visiting Lecturer with University City Dublin, Dublin, and Dublin Business School, Dublin. She is currently the Research Coordinator for the Trinity Access 21 Programme, lectures on the undergraduate psychology degree in Trinity College Dublin and on the foundation course in the Trinity Access Programme.

Kevin Sullivan received the B.Sc. degree in applied science (computer science and software engineering) from the Dublin Institute of Technology, Dublin, Ireland, in 2002, and the M.Sc. degree in technology and learning from the University of Dublin (Trinity College), Dublin, in 2012, where he is currently pursuing the Ph.D. degree in computer science.

Since 2009, he has been the Development Manager with Bridge21, Trinity College Dublin. 